\title{
DISPLACED SUPRACONDYLAR HUMERAL FRACTURES;
}

TREATMENT AMONG CHILDREN: CROSSED VERSUS LATERAL PINNING

\author{
DR. ZAKIR ALI SHAH, DR. UZMA ARIF
}

ABSTRACT... Objective: To compare outcome of patients with supracondylar fractures of humerus treated by cross $k$ wires and lateral entry k wires in children. Study Design: Randomized controlled trial study. Place and duration of study: January 2012 to December 2012 at Department of Orthopedics, Nawaz Sharif Social Security hospital, Lahore. Subjects and Methods: Two hundred patients, meeting the selection criteria were identified. These patients were divided into group $A$ and group $B$ randomly. In group $A$ cross $k$ wire fixation and in group B lateral entry $k$ wire fixation was performed. Loss of reduction was assessed and recorded in the immediate postoperative period and three weeks later at the time of removal of k wires. Range of motion of the elbow, in the form of excellent outcome was assessed at the end of 12 weeks postoperatively. Results: A total of 200 patients were included in the study. Loss of reduction was found in thirty patients (30\%) in group A and in forty one patients (41\%) in group B. In group A, seventy two patients (72\%) had excellent outcome while twenty eight patients (28\%) did not gain the desired range of motion at elbow. In group B, sixty five patients (65\%) had excellent outcome while in thirty five patients (35\%), the desired range of motion at elbow was not achieved. No neurological injury occurred with both configurations. Conclusions: Lateral entry k wire fixation is as effective as cross $\mathrm{k}$ wire in the treatment of displaced supracondyler fracture of humerus in children.

Key words:Anterior Humeral line, loss of reduction, Baumann `s angle.

Article Citation

Shah ZA, Arif U. Displaced Supracondylar Humeral Fractures; Treatment among children: crossed versus lateral pinning. Professional Med J 20(5): 818-824.

\section{INTRODUCTION}

Supracondyler fractures of the distal humerus are the most common (60\%) of elbow fracture in children ${ }^{1}$ and represents approximately $16.6 \%$ of all fractures in children ${ }^{1,2,3}$. In general fractures in children are treated conservatively. Closed reduction with percutaneous pin fixation has become the treatment of choice for displaced supracondylar fractures of the humerus among children either lateral entry k-wires or cross kwires. Successful management involves avoiding early ulnar nerve injury, re displacement and late malunion complications ${ }^{3,4}$. There still remain several controversial topics with regard to the treatment of these injuries, including the pin placement configuration, urgency of operative treatment, whether type II supracondyler fracture should be treated operatively or non operatively and the management of dysvascular limb ${ }^{5,6,7}$. In our set up both of the methods are used, but cross $k$ wires are associated with iatrogenic injury to the ulnar nerve (0\% to $5 \%$ ). Loss of reduction in lateral entry $\mathrm{k}$ wires occurred due to technical fault in $14 \%$ patients in different studies and
$3 \%$ in cross $\mathrm{k}$ wires ${ }^{5}$. Excellent outcome in the form of range of motion was $91 \%$ in lateral entry $\mathrm{k}$ wire fixation and $66 \%$ in cross $k$ wire fixation ${ }^{5,6}$. The purpose of this study was to compare the outcome of patients with supracondylar fractures of humerus treated by cross $\mathrm{k}$ wires and lateral entry $\mathrm{k}$ wires in children.

\section{MATERIAL AND METHODS}

\section{SAMPLE SELECTION}

Inclusion criteria

1. Patients with age 3-10 years

2. Gartland type II, III fractures.

3. Supracondylar fractures of humerus within one week of injury.

\section{Exclusion criteria}

1. Supracondylar fractures of humerus with vascular or nerve injury (clinical assessment) and with ipsilateral forearm fractures.

2. Open supracondylar fractures of humerus. 


\section{DATA COLLECTION PROCEDURE}

200 patients who presented to emergency with displaced supracondylar fracture of humerus meeting our inclusion criteria were admitted in the hospital. Radiographs of affected side were performed in anteroposterior and lateral projections. Evaluation of vascular and neurological status was carried out. After explanation of the procedure, the informed consent was taken for the surgery and study. The demographic profile was recorded. All baseline investigations were performed. Operative intervention was arranged for either same day or the following morning. These patients are divided into two groups, Group A \& B, using lottery method, each group containing 100 patients. Patients in group A underwent cross k-wire fixation and patients in group $B$ underwent lateral entry k-wire fixation. Operative procedure was performed by orthopedic surgeon.

All the patients were kept nil by mouth for 6 hours before induction of general anesthesia. The patients were placed supine with the injured upper limb at the side of operating table. Image intensifier was placed along the table from caudal end of the patient. After thorough scrubbing and then draping of injured elbow, closed manipulative reduction was performed and the reduction was confirmed with image intensifier. If the reduction was acceptable k-wires $(0.062 \mathrm{~mm})$ were passed under image intensifier, cross k-wires in group $A$ and lateral entry k-wires in group $B$. If the reduction was not acceptable another one or two more attempts of closed reduction were performed, if still acceptable reduction is not achieved then open reduction and $k$ wire fixation, cross k-wire(group A) or lateral entry kwire(group B) was carried out. Immediate postoperative $x$ rays of operated elbow were taken in true anteroposterior and true lateral views to document loss of reduction if present, by measuring Baumann's ìs angle and anterior humeral line.

After the discharge, all the patients were followed up at outpatient department. At 3rd postoperative week k- wires were removed and operated elbow was assessed again by taking $x$ rays. Bauman ìs angle and anterior humeral lines were drawn on the x rays, values were recorded and compared. Deviation from the normal values of either the Bauman s angle or anterior humeral line, were considered loss of reduction. After the removal of the back slab gentle range of motion exercises of the operated elbow were started and any loss of range of motion of the elbow were recorded at the end of 12th week postoperatively in the form of excellent outcome according to Flynn s criteria. The data collected were processed for statistical analysis with the SPSS 17. For crude analysis of independent groups of data, the chi-square test and t-test was used; $p<0.05$ was considered significant.

\section{RESULTS}

This study was conducted on patients who underwent $\mathrm{K}$ wire fixation for displaced supracondyler fracture in children by two different methods i.e. Cross $k$ wire fixation (group A) (Figure 1) and Lateral entry k wire fixation (group B) (Figure 2).

A total of 200 patients were treated, 100 in each group. These patients were followed for 12 weeks after the date of operation. The mean age of the patients in Cross $k$ wire group A was $6.51 \pm 2.26$ years and $5.83 \pm 1.83$ years in lateral entry group $B$. In group $A$, 59 patients $(59 \%)$ were in range of 3 to 6 years and 41 patients (41\%) were in range of 7 to 10 years. Similarly in group B, 58 patients (58\%) were in range of 3 to 6 years and 42 patients (42\%) were in range of 7 to 10 years. (Table-I)

Key: SD = Standard deviation, Group $A=$ Cross kwires, Group B = Lateral entry k-wires

In group A, 80 patients (80\%) were male and 20 patients $(20 \%)$ female. Male to female ratio was 4.0:1.In group B, 78 patients (78\%) was male and 22 patients $(22 \%)$ were female with male to female ratio of 3.54:1 (Table-II). 


\begin{tabular}{|c|c|c|c|c|}
\hline \multirow{2}{*}{$\begin{array}{c}\text { Age in } \\
\text { years }\end{array}$} & \multicolumn{2}{|c|}{ Group A (n=100) } & \multicolumn{2}{c|}{ Group B $(\mathbf{n = 1 0 0 )}$} \\
\cline { 2 - 5 } & $\begin{array}{c}\text { No. of } \\
\text { patients }\end{array}$ & \%age & $\begin{array}{c}\text { No. of } \\
\text { patients }\end{array}$ & \%age \\
\hline $3-6$ & 59 & 59.0 & 58 & 58.0 \\
\hline $7-10$ & 41 & 41.0 & 42 & 42.0 \\
\hline Total & 100 & 100.0 & 100.0 & 100.0 \\
\hline \multicolumn{3}{|c|}{ Table-I. Age Distribution of Patients in Both } \\
Groups ( $n=200)$ \\
Mean \pm SD:
\end{tabular}

\begin{tabular}{|c|c|c|c|c|}
\hline \multirow{2}{*}{$\begin{array}{c}\text { Baumann's } \\
\text { angle }\end{array}$} & \multicolumn{2}{|c|}{ Group A $(\mathbf{n = 1 0 0 )}$} & \multicolumn{2}{c|}{ Group B $(\mathbf{n = 1 0 0 )}$} \\
\cline { 2 - 5 } & $\begin{array}{c}\text { No. of } \\
\text { patients }\end{array}$ & \%age & $\begin{array}{c}\text { No. of } \\
\text { patients }\end{array}$ & \%age \\
\hline $\begin{array}{c}\text { Normal } \\
\left(64 \text { to } 81^{\circ}\right)\end{array}$ & 94 & 94.0 & 82 & 82.0 \\
\hline $\begin{array}{c}\text { Abnormal } \\
\left(<64 \text { and }>81^{\circ}\right)\end{array}$ & 6 & 6.0 & 18 & 18.0 \\
\hline
\end{tabular}

Table-III. Comparison of Immediate Postoperative Period Baumann's Angle in Both Group $(\mathrm{n}=200)$
$M e a n \pm S D$ :
$74.90 \pm 6.85$
$77.60 \pm 4.40$
$P$ value 0.009

\begin{tabular}{|c|c|c|c|c|}
\hline \multirow{2}{*}{ Gender } & \multicolumn{2}{|c|}{ Group A $(\mathbf{n = 1 0 0 )}$} & \multicolumn{2}{c|}{ Group B $(\mathbf{n = 1 0 0 )}$} \\
\cline { 2 - 5 } & $\begin{array}{c}\text { No. of } \\
\text { patients }\end{array}$ & \%age & $\begin{array}{c}\text { No. of } \\
\text { patients }\end{array}$ & \%age \\
\hline Male & 80 & 80.0 & 78 & 78.0 \\
\hline Female & 20 & 20.0 & 22 & 22.0 \\
\hline
\end{tabular}
Table-II. Sex Distribution of Patients in
Both Groups ( $\mathrm{n}=200)$
Male to female ratio: 4.0:1

\begin{tabular}{|c|c|c|c|c|}
\hline \multirow{2}{*}{$\begin{array}{l}\text { Anterior humeral } \\
\text { line }\end{array}$} & \multicolumn{2}{|c|}{ Group A $(n=100)$} & \multicolumn{2}{|c|}{ Group $B(n=100)$} \\
\hline & $\begin{array}{l}\text { No. of } \\
\text { patients }\end{array}$ & \%age & $\begin{array}{l}\text { No. of } \\
\text { patients }\end{array}$ & \%age \\
\hline Intact & 70 & 70.0 & 59 & 59.0 \\
\hline Not intact & 30 & 30.0 & 41 & 41.0 \\
\hline \multicolumn{5}{|c|}{$\begin{array}{l}\text { Table-IV. Comparison of Immediate Postoperative } \\
\text { Anterior Humeral Line of Patients in Both Groups }(\mathrm{n}=\mathbf{2 0 0}) \\
\text { Chi-square test } \quad 2.64, \quad P \text { value } 0.10\end{array}$} \\
\hline
\end{tabular}

No neurological injury occurred with both configurations. The normal Baumann's angle is between 64 to 81 degrees (average 72 degrees) on anteroposterior radiograph. In group $\mathrm{A}$, in immediate postoperative period $94(94 \%)$ patients has normal Baumann 's and in 6 patients (6\%) it was abnormal. The mean Baumann's angle (and standard deviation) was $74.90 \pm 6.85$. In group $B$, in immediate postoperative period 82 patients (82\%) had normal Baumann's angle and 18 patients (18\%) had abnormal angle. The mean Baumann's angle (and standard deviation) was $77.60 \pm 4.40$ and $P$ value was 0.009 (Table-III).

Anterior humeral line was intact in 70 patients (70\%) and not intact in 30 patients (30\%) in group A. Similarly anterior humeral line was intact in 59 patients (59\%) and not intact in 41 patients (41\%) in group B, in immediate postoperative period. The Chi-square value

of two groups was 2.64 with P value of 0.10 (Table-IV).

Comparison of Baumann `angle was also done at the time of removal of $k$ wires ( 3 weeks after the date of operation), In group A, in 90 patients $(90 \%)$ the Baumann 's angle was normal while in 10 patients $(10 \%)$ it was abnormal. The mean Baumann `s angle (and standard deviation) was 77.50 \pm 5.09 . In group B, it was normal in 78 patients $(78 \%)$ and abnormal in 22 patients (22\%) with mean (and standard deviation) of $77.70 \pm 6.30$ and $P$ value of 0.021 (Table-V).

There was almost no change in the anterior humeral line at the time of union i.e. 3 weeks postoperatively between groups. Anterior humeral line was intact in 70 patients $(70 \%)$ and not intact in 30 patients $(30 \%)$ in group A. Similarly anterior humeral line was intact in 59 patients (59\%) and not intact in 41 patients (41\%) in group B, 3rd postoperative week. The difference 


\begin{tabular}{|c|c|c|c|c|}
\hline \multirow{2}{*}{$\begin{array}{l}\text { Baumann's } \\
\text { angle }\end{array}$} & \multicolumn{2}{|c|}{ Group A $(n=100)$} & \multicolumn{2}{|c|}{ Group B $(n=100)$} \\
\hline & $\begin{array}{c}\text { No. of } \\
\text { patients }\end{array}$ & $\%$ age & $\begin{array}{c}\text { No. of } \\
\text { patients }\end{array}$ & \%age \\
\hline $\begin{array}{l}\text { Normal } \\
\left(65 \text { to } 82^{\circ}\right)\end{array}$ & 90 & 90.0 & 78 & 78.0 \\
\hline $\begin{array}{c}\text { Abnormal } \\
\left(<64 \&>81^{\circ}\right)\end{array}$ & 10 & 10.0 & 22 & 22.0 \\
\hline \multicolumn{5}{|c|}{$\begin{array}{l}\text { Table-V: Comparison of Baumann's Angle after 3rd } \\
\text { Postoperative Week in Both Groups }(\mathbf{n}=200)\end{array}$} \\
\hline
\end{tabular}

\begin{tabular}{|c|c|c|c|c|}
\hline \multirow{2}{*}{$\begin{array}{c}\text { Anterior } \\
\text { humeral } \\
\text { line }\end{array}$} & \multicolumn{2}{|c|}{ Group A $(\mathbf{n = 1 0 0 )}$} & \multicolumn{2}{c|}{ Group B (n=100) } \\
\cline { 2 - 5 } & $\begin{array}{c}\text { No. of } \\
\text { patients }\end{array}$ & \%age & $\begin{array}{c}\text { No. of } \\
\text { patients }\end{array}$ & \%age \\
\hline Intact & 70 & 70.0 & 59 & 59.0 \\
\hline Not intact & 30 & 30.0 & 41 & 41.0 \\
\hline
\end{tabular}

Table-VI. Comparison of Anterior Humeral Line after 3rd Postoperative Week in Both Groups $(n=200)$ Chi-square test 2.64, $\quad P$ value 0.10

\begin{tabular}{|c|c|c|c|c|}
\hline \multirow{2}{*}{$\begin{array}{c}\text { Loss } \\
\text { reduction }\end{array}$} & \multicolumn{2}{|c|}{ Group A (n=100) } & \multicolumn{2}{c|}{ Group B (n=100) } \\
\cline { 2 - 5 } & $\begin{array}{c}\text { No. of } \\
\text { patients }\end{array}$ & \%age & $\begin{array}{c}\text { No. of } \\
\text { patients }\end{array}$ & \%age \\
\hline Yes & 30 & 30.0 & 41 & 41.0 \\
\hline No & 70 & 70.0 & 59 & 59.0 \\
\hline
\end{tabular}

Table-VII. Comparison of Loss of Reduction 3 weeks Postoperatively in Both Groups $(\mathbf{n}=\mathbf{2 0 0})$ Chi-square test 2.64, $P$ value 0.10

between the two groups was 2.64 (Chi-square test) with $P$ value of 0.10 (Table-VI).

So at the end of 3rd postoperative week 30 patients (30\%) in group $A$ had loss of reduction of fracture while seventy patients (70\%) had no loss with stable reduction. In group B, forty one patients (41\%) had loss of reduction and 59 patients (59\%) had stable construct of fracture reduction with Chi-square test 2.64 and $\mathrm{P}$ value of 0.10 (Table-VII).

Comparison of range of motion in the form of excellent outcome has also been done between two groups. In group A 72 patients (72\%) had excellent outcome while 28 patients (28\%) did not gain the desired range

\begin{tabular}{|c|c|c|c|c|}
\hline \multirow{2}{*}{$\begin{array}{c}\text { Excellent } \\
\text { Outcome }\end{array}$} & \multicolumn{2}{|c|}{ Group A $(\mathbf{n = 1 0 0 )}$} & \multicolumn{2}{c|}{ Group B $(\mathbf{n = 1 0 0 )}$} \\
\cline { 2 - 5 } & $\begin{array}{c}\text { No. of } \\
\text { patients }\end{array}$ & \%age & $\begin{array}{c}\text { No. of } \\
\text { patients }\end{array}$ & \%age \\
\hline Yes & 72 & 72.0 & 65 & 65.0 \\
\hline No & 28 & 28.0 & 35 & 35.0 \\
\hline
\end{tabular}

Table-VIII. Comparison of Excellent Outcome (0-5) degree after 12 Postoperative Weeks in Both Groups $(n=200)$ Chi-square test $1.13, \quad P$ value 0.28

\begin{tabular}{|c|c|c|}
\hline $\begin{array}{l}\text { Baumann Angle: } \\
\text { imm. Post op } \\
\text { (Mean } \pm \text { SD) }\end{array}$ & $\begin{array}{l}\text { Baumann Angle: } \\
\text { after } 3 \text { weeks } \\
\text { (Mean } \pm \text { SD) }\end{array}$ & P-value \\
\hline $74.88 \pm 6.79$ & $77.50 \pm 5.09$ & 0.014 \\
\hline $\begin{array}{l}\text { Ant. Humeral line: } \\
\text { imm. Post op }\end{array}$ & $\begin{array}{l}\text { Ant. Humeral line: } \\
\text { after } 3 \text { weeks }\end{array}$ & \\
\hline $1.30 \pm 0.46$ & $1.30 \pm 0.45$ & 1.0 \\
\hline \multicolumn{3}{|c|}{$\begin{array}{l}\text { Table-IX. Comparison of Baumann's angle and Anterior } \\
\text { humeral line in the immediate postoperative period and } 3 \\
\text { weeks later at the time of removal of } k \text { wire in Group A } \\
(n=100)\end{array}$} \\
\hline
\end{tabular}

\begin{tabular}{|c|c|c|}
\hline $\begin{array}{c}\text { Baumann Angle: } \\
\text { imm. Post op } \\
\text { (Mean } \pm \text { SD) }\end{array}$ & $\begin{array}{c}\text { Baumann Angle: } \\
\text { after 3 weeks } \\
\text { (Mean } \pm \text { SD) }\end{array}$ & P-value \\
\hline $77.60 \pm 4.40$ & $77.70 \pm 6.30$ & 0.897 \\
\hline $\begin{array}{c}\text { Ant. Humeral line: } \\
\text { imm. Post op }\end{array}$ & $\begin{array}{c}\text { Ant. Humeral line: } \\
\text { after 3 weeks }\end{array}$ & \\
\hline $1.41 \pm 0.49$ & $1.41 \pm 0.49$ & 1.0 \\
\hline
\end{tabular}

Table-X. Comparison of Baumann's angle and Anterior humeral line in the immediate postoperative period and 3 weeks later at the time of removal of $k$ wire in Group B $(n=100)$

of motion at elbow. In group B, 65 patients (65\%) had excellent outcome while in 35 patients $(35 \%)$ the desired range of motion at elbow was not achieved. Chi-square test was 1.13 and $P$ value of 0.28 (TableVIII).

Comparison of Baumann's angle in the immediate postoperative period and 3 weeks later at the time of removal of $k$-wires performed in group $A$. The immediate post op Baumann's angle mean and standard deviation was $74.88 \pm 6.79$ and after 3 
weeks it was $77.50 \pm 5.09$ with $p$ value of $<0.014$.

The mean anterior humeral line in the immediate post op period was $1.30 \pm 0.46$ and after 3 weeks it was $1.30 \pm 0.45$ with $p$-value of 1.0 (Table-IX).

Comparison of Baumann's angle in the immediate postoperative period and 3 weeks later at the time of removal of k-wires performed in group $B$. The immediate post op Baumann's angle mean and standard deviation was $77.60 \pm 4.40$ and after 3 weeks it was $77.70 \pm 6.30$ with $p$-value of 0.897 . The mean anterior humeral line in the immediate post op period was $1.41 \pm 0.49$ and after 3 weeks it was

\section{DISCUSSION}

Closed reduction and percutaneous pin fixation for the management of supracondylar humeral fractures in children have gained wide popularity, but the optimal pin configuration remains controversial ${ }^{8}$. In present study the outcome of cross k-wires and lateral entry $\mathrm{k}$-wires in the treatment of supracondylar fracture has been compared. 200 cases were studied with majority of cases were of Gartland type III fractures in both groups. $80 \%$ of patients were male involving the dominant upper extremity. No neurological injury occurred with both configurations of pins because in doubtful cases with a massively swollen elbow, a small incision was made to save ulnar nerve from injury.

In our study the mean Baumann's angle with standard deviation was comparable to the study done by Baumann $\mathrm{E}$. The second parameter for determination of loss of reduction was anterior humeral line. In our study the anterior humeral line was not intact in 30\% patient in cross $k$ wire group (A) and it was also not intact in $41 \%$ patient in lateral entry group (B), in the immediate postoperative period and at 3 weeks at the time of fracture healing. In the study by David $L$ et $\mathrm{al}^{13}$, the anterior humeral line was not intact in $4 \%$ of patients in lateral entry group and $3 \%$ in cross $k$-wire group. There were many factors responsible for worse result in our study. In our set up procedures were performed by different consultants, some of them not having enough experience in children 's fracture reduction. In some patients the size of $k$ wires was also not appropriate and the last but not the least geometry of fracture especially type IV fracture which has greatest difficulty in reduction. We also followed our patients for 3 months after date of operation to assess the range of motion in the form of excellent outcome according to Flynn criteria. Patients were seen on weekly basis after the wire removal to gain the maximum range of motion of operated elbow. In cross k-wire fixation the excellent outcome was $72 \%$ in lateral entry k-wire fixation it was $65 \%$. We did not gained the desired range of motion i.e. excellent outcome in $28 \%$ of patients in cross pinning and $35 \%$ patients in lateral entry pin fixation. In the study by Flynn et al, in cross k-wire fixation the excellent outcome was $81 \%$. The reasons for slightly worse results in our study were a) delay in the removal of $\mathrm{k}$ wires due to late presentation b) compliance of the patient and their parents not following protocols for physiotherapy c) technical factors in fixation of the displaced fractures.

In our study, we found no significant differences in terms of loss of reduction, the Baumann's angle, elbow motion and iatrogenic ulnar nerve injury between the two primary treatments methods involving use of either crossed or two lateral $\mathrm{K}$ - wires. The reported risk of loss of reduction following lateral $\mathrm{K}$ - wire fixation has also varied widely. A recent systematic review of comparing cross pin fixation with lateral entry pin fixation revealed cross pin entry provides a more stable configuration, and the probability of deformity or loss of reduction is 0.58 times lower than with isolated lateral pin entry, the rate of displacement following lateral entry pin fixation was $2.1 \%$. When the prospective studies alone were analyzed, there were no significant difference in the probability of iatrogenic nerve injury or deformity and 
displacement ${ }^{9}$. Skaggs et al. reported no loss of reduction after fixation of fifty-five type-III fractures with two or three lateral entry pins. The risk of displacement after lateral entry pin fixation can be reduced by emphasizing proper pin placement technique, with divergent pins, pins that engage the lateral and central columns, and use of a third lateral pin if needed ${ }^{10,11}$.

Lateral entry pin fixation has been compared with cross entry fixation in numerous retrospective case series of extension supracondylar fractures of the humerus in Children. In a review of fifty two completely displaced extension type supracondylar fractures of humerus treated with two different pin fixation techniques Kocher et al. found no patient in either group had a major loss of reduction. Six of the twentyeight patients treated with lateral entry and one of the twenty-four treated with cross entry had a mild loss of reduction; this was not a significant difference. There were no cases of iatrogenic ulnar nerve injury in either group $^{12}$. Skaggs et al. reported no difference in maintenance of reduction between the two methods, but iatrogenic ulnar nerve injury was seen in $10.6 \%$ (seventeen) of 160 cases treated with a medial pin $^{13}$. In a study of forty-seven children in whom a type-III supracondylar fracture had been treated with crossed pins (twenty-seven patients) or with lateral pins only (twenty). Topping et al. found no loss of reduction in either group and one ulnar nerve injury in the group with crossed pins ${ }^{14}$.

Similarly, in a study of fifty-six fractures, Shamsuddin et al. found three iatrogenic ulnar nerve injuries associated with medial and lateral entry pin fixation and two iatrogenic radial or anterior interosseous nerve injuries associated with lateral entry pin fixation, although there was no difference in loss of reduction ${ }^{15}$.

Foead et al. performed a randomized clinical trial in which thirty-four type-II or III fractures were treated with cross pin fixation and thirty-two were treated with lateral pin fixation ${ }^{16}$. Straight lateral skin traction was used prior to closed reduction and pinning. There were no significant differences in terms of loss of reduction, the Baumann angle, or elbow motion widely between the two groups. There were five iatrogenic ulnar nerve injuries in the cross entry group, and there were two iatrogenic ulnar nerve injuries and one iatrogenic radial nerve injury in the lateral entry group. Based on these clinical and radiological parameters, we were not able to find any difference in the loss of reduction and iatrogenic ulnar nerve injury with the 2 methods of pin fixation. All patients had their reduction performed under the guidance of an image intensifier. Since the enrolments of both groups were randomized, and the standard protocol of reduction was applied for both groups. Therefore, we can consider that there was no difference in the stability of fixation and iatrogenic ulnar nerve injury caused by either the cross pin fixation or 2- lateral pin fixation.

\section{CONCLUSIONS}

It was concluded that there were no significant difference in the stability provided by cross K- wire fixation and 2- lateral K-wire fixation in both coronal and Sagittal planes. There was also no difference in the incidence of ulnar nerve injuries between the 2 methods of fixation, although there is a trend to suggest that more injury occurred in the cross K-wire fixation group. In doubtful cases with a massively swollen elbow, a small incision can save the ulnar nerve from injury.

Copyright@ 02 Aug, 2013.

\section{REFERENCES}

1. Otsuka NY, Kasser JR. Supracondylar fractures of the humerus in children. J Am Acad Orthop Surg. 1997; 5:19-26.

2. Dim eglio A. Growth in pediatric orthopaedics. In: Morrissy RT, Weinstein SL, editors. Lovell and winter's pediatric orthopaedics. Philadelphia: Lippincott Williams and Wilkins; 2005. p. 35-65.

3. Cheng JC, $\mathrm{Ng} \mathrm{BK}$, Ying SY, Lam PK. A 10-year study of the changes in the pattern and treatment of 6,493 fractures. J Pediatr Orthop. 1999; 19:344-50. 
4. Kasser JR, Beaty JH. Supracondylar fractures of the distal humerus. In: Beaty JH, Kasser JR, Wilkins KE, Rockwood CE, editors. Rockwood and Wilkins' fractures in children. Philadelphia: Lippincott Williams and Wilkins; 2006. p. 543-89.

5. Cheng JC, Lam TP, Maffulli N. Epidemiological features of supracondylar fractures of the humerus in Chinese children. J Pediatr Orthop B. 2001; 10:637.

6. Farnsworth CL, Silva PD, Mubarak SJ. Etiology of supracondylar humerus fractures. J Pediatr Orthop. 1998; 18:38-42.

7. Mahan ST, May CD, Kocher MS. Operative management of displaced flexion supracondylar humerus fractures in children. $J$ Pediatr Orthop. 2007; $27: 551-6$.

8. Bronfen CE, Geffard B, Mallet JF. Dissolution of the trochlea after supracondylar fracture of the humerus in childhood: an analysis of six cases. $J$ Pediatr Orthop. 2007; 27:547-50.

9. Brauer CA, Lee BM, Bae DS, Waters PM, Kocher MS. A systematic review of medial and lateral entry pinning versus lateral entry pinning for supracondylar fractures of the humerus. J Pediatr Orthop 2007; 27:181-6.

10. Skaggs DL, Cluck MW, Mostofi A, Flynn JM, Kay RM. Lateral-entry pin fixation in the management of supracondylar fractures in children. J Bone Joint Surg Am 2004; 86:702-7.
11. Davis RT, Gorczyca JT, Pugh K. Supracondylar humerus fractures in children. Comparison of operative treatment methods. Clin Orthop Relat Res 2000; 376:49-55.

12. Kocher MS, Kasser JR, Waters PM, Bae D, Snyder $\mathrm{BD}$, Hresko MT, et al. Lateral entry compared with medial and lateral entry pin fixation for completely displaced supracondylar humeral fractures in children. A randomized clinical trial. J Bone Joint Surg Am 2007; 89:706-12.

13. Skaggs DL, Hale JM, Bassett J, Kaminsky C, Kay RM, Tolo VT. Operative treatment of supracondylar fractures of the humerus in children. The consequence of pin placement. J Bone Joint Surg Am 2001; 83:735-40.

14. Topping RE, Blanco JS, Davis TJ. Clinical evaluation of crossed-pin versus lateral-pin fixation in displaced supracondylar humerus fractures. J Pediatr Orthop 1995; 15:435-9.

15. Shamsuddin SA, Penafort R, Sharaf I. Crossed-pin versus lateral-pin fixation in pediatric supracondylar fractures. Med J Malaysia 2001; 56:38-44.

16. Foead A, Penafort R, Saw A, Sengupta S. Comparison of two methods of percutaneous pin fixation in displaced supracondylar of the humerus in children. J Orthop Surg 2004; 12:76-82.1.41 \pm 0.49 with $p$-value of 1.0 (Table- $X$ ).

\section{AUTHOR(S):}

1. DR. ZAKIR ALI SHAH, FCPS (Ortho)

Assistant Professor University of Lahore Nawaz Sharif Social Security Hospital

2. DR. UZMA ARIF

Trainee Registrar SZH (FCPS-I Radiology)
Correspondence Address:

Dr. Zakir Ali Shah

112/A Judicial Colony, Lalazar Phase-I,

Thokar Niaz Baig, Lahore

drzakiralishah@gmail.com

\section{PREVIOUS RELATED STUDIES \\ Mukhtar Ahmed, Asghar Ali, Muhammad Shafi. SUPRACONDYLAR FRACTURES; COMPARISON OF MEDIAL AND LATERAL APPROACH FOR FIXATION OF HUMERUS IN CHILDREN (Original) Prof Med Jour 13(2) 244-252Apr, May, Jun, 2006. \\ Noor Akbar Sial, Abid Rashid, Ajmal Yasin. SUPRACONDYLAR HUMERUS FRACTURES; OUTCOME OF OPEN REDUCTION AND PERCUTANEOUS CROSSED PIN FIXATION (Original) Prof Med Jour 18(1) 147-153 Jan, Feb, Mar 2011.}

